\title{
Tumor Grading System
}

National Cancer Institute

\section{Source}

National Cancer Institute. Tumor Grading System. NCI Thesaurus. Code C48224.

A morphologic classification system of malignant tumors, usually relating to disease progression and clinical outcome. It is based upon the presence or absence of several morphologic parameters, including tumor cell necrosis, cytologic atypia, nuclear pleomorphism and mitotic figures, the architectural infiltrating patterns, and the degree of tumor cell differentiation. Malignant tumors usually are graded I-III. 